\title{
Performance Investigation of Grid-Connected DFIG using Integrated Shunt Active Filtering Capabilities
}

\author{
Krishna S. Patel ${ }^{1, *}$, Vijay H. Makwana² \\ ${ }^{1} \mathrm{Ph} . \mathrm{D}$. research scholar, Gujarat Technological University, Gujarat-382424, India \\ ${ }^{2}$ Professor in Electrical Department, G H Patel College of Eng. \& Tech., Gujarat-388120, India
}

\begin{abstract}
This paper presents the modified grid side converter control (GSC) technique which enable the GSC to work as a shunt active filter to mitigate the grid current harmonics produced by the nonlinear load, as well as to transfer power from the grid to the rotor of doubly fed induction generator (DFIG) or vice versa. The main contribution of this proposed technique is an addition of a shunt active filter with space vector pulse width modulation (SVPWM) controller in GSC control itself in order to achieve a better grid current \%THD profile, and simultaneously to control active power for variable wind speed. The reactive power supply to the DFIG and extraction of maximum power is achieved using RSC. The comparison of the modified GSC control technique using hysteresis current control (HCC), and SVPWM controller used to mitigate the harmonics is presented with different wind speeds. The proposed modified GSC control technique is simulated for grid-connected 2.6 MW DFIG based wind energy conversion system (WECS) in MATLAB Simulink environment.
\end{abstract}

\section{Introduction}

The energy consumption is rising significantly worldwide due to the increase in industrialization and population. Due to the limited availability of conventional energy sources and environmental concern, the future demands of energy lead towards renewable energy sources [1]. The major advantages of renewable energy sources are unlimited in nature, eco-friendliness and freely available. The per-unit rate of wind power generation is low as compared to other renewable energy sources [2]. Consequently, wind energy is the most favored energy sources compared to other energy sources. According to the global wind market statistics carried out by the world wind energy association (WWEA), the overall capacity of wind turbines installed worldwide by the end of 2019 reached $600 \mathrm{GW}$, a 54 GW increase from the previous year. [3]

F. Blaabjerg and Zhe Chen [4] explained the latest development in the power electronics field which helps to understand wind power generation and its controls. A comprehensive review of the wind power generators demonstrated that they are able to run at adjustable speeds with high efficiency using the advanced power electronic converter topologies discussed in [5]. Amongst all variable speed wind turbines, DFIG is the most widely preferred choice for WECS because of its low cost, high efficiency, better utilization of converters, low converter rating and high energy output [6]. As the rotor rating of DFIG is nearly $\pm 30 \%$ of rated stator power, the size and rating of the converter reduce drastically compared to the converter used in other types of wind generators [7]. DFIG can feed power to the grid through both stator and rotor terminals, which has added advantages for DFIG.

Mohd. Hasan Ali [8] illustrated the quality of grid power and DFIG power which is of prime importance in today's era. Mostly the non-linear load plays a vital role to deteriorate the power quality of the grid. Many techniques were proposed in the literature to mitigate the grid current harmonics with reactive power control [9]. The additional converters used as a shunt active filter for controlling the reactive power and compensating the harmonics were presented in [10]. However, the additional converter will increases model complexity and cost. Mehni T. et. al. [11] presented the harmonics compensation and reactive power control using a modified RSC control structure. Subsequently, harmonics compensation using a modified RSC control structure is discussed in [12]. But the problem of a modified RSC control structure can lead to inject highfrequency harmonics in the rotor of the DFIG. This can increase noise and losses inside the machine. Highfrequency harmonics also create a mechanical imbalance in the rotating part of the machine. The drawback of modified RSC control can be removed with the help of a modified GSC control technique.

N.K. Naidu and his colleague [13] proposed conventional hysteresis current control (HCC) based GSC control technique for the mitigation of harmonics from grid current. The incorporation of a shunt active filter (SAF) phenomenon in the existing control technique of GSC provides compensation current in a 
grid for harmonics mitigation. The HCC based modified GSC control technique is also capable of controlling active power flow. However, the major issues with the conventional HCC are random switching, high heat losses, and chances of a dead short circuit in the converter legs due to random switching and poor dynamic response of the system. Also, the authors have not discussed the operation of DFIG for different wind speeds under nonlinear load conditions.

Hence, to provide a better solution of harmonics mitigation under nonlinear load condition for variable wind speed, there is a need to develop a new GSC control technique which can solve the above-cited problem. Therefore, in this paper, the authors have proposed a novel SVPWM based modified GSC control technique which can behave as a shunt active filter during the nonlinear load condition to mitigate the harmonics from grid current in variable wind speed conditions.

\section{DFIG based WECS configuration}

Fig. 1 shows the basic block diagram of a grid-connected DFIG based WECS system. It consists of a wind turbine, a gearbox, a wind generator (DFIG), back-to-back converters, a grid filter, a power transformer, and a diode bridge rectifier as a non-linear load. The stator of DFIG is directly connected to the grid, while the rotor is connected to the grid through the back-to-back converters. The capacitor is placed between the back-toback converters to filter out the ripple content, to provide reactive power and to maintain constant DC link voltage. Mona N. et. al. [14] discussed the power rating of the RSC is essentially $30 \%$ of the total stator power rating of DFIG. Due to that, the power losses in the converters are low, also contributing to increasing overall efficiency. The RSC controls the power flow from the stator to the grid by controlling the rotor currents [15]. Flux oriented control algorithm is applied to the rotor side converter and voltage control algorithm applied to the grid side converter for smooth power flow control.

\section{Control Technique For DFIG Based WECS}

The control technique of RSC and GSC is discussed in detail in this section. Fig. 2 shows a schematic diagram of grid-connected DFIG with RSC and GSC control structure.

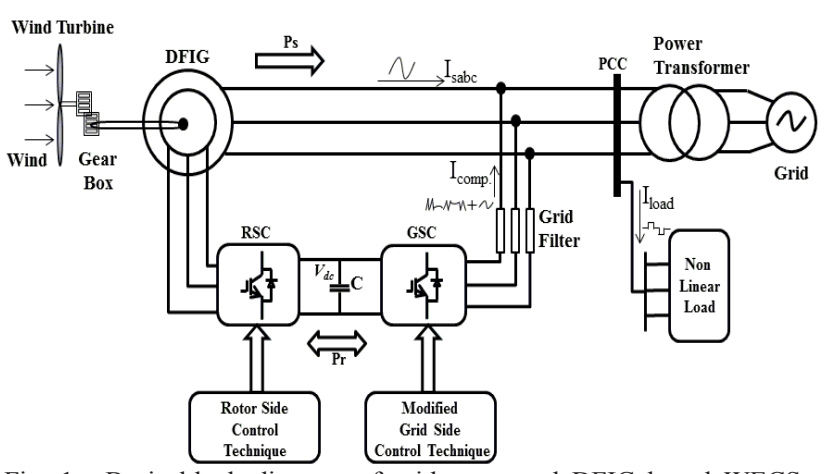

Fig. 1. Basic block diagram of grid-connected DFIG based WECS system

\subsection{Rotor side converter (RSC) control technique:}

There are many control techniques proposed for controlling torque and stator reactive power using RSC of DFIG but the vector control technique is the most preferable amongst all other techniques [16]. Also, the maximum power point tracking (MPPT) algorithm is added in the RSC side control technique to get maximum power from variable wind speed.

The mechanical power capture from the wind power given by:

$P_{M}=\frac{1}{2} \rho A v_{w}{ }^{3} C_{p}$

$\lambda_{T, \text { opt }}$ (Optimal tips speed ratio) is also considered during the calculation of maximum power. The speed at which maximum power $P_{M}$ produced is related to $\lambda_{T, o p t}$ and wind speed $v_{w}$ is expressed as follow:

$w_{M}=\lambda_{T, o p t} \frac{v_{w}}{r_{T}}$

It is concluded from (1) and (2) that to capture the maximum power at variable wind speed, the turbine speed must be adjusted such that optimal tip speed ratio $\lambda_{T, \text { opt }}$ is maintained.

The relation between $P_{M}$ and $w_{M}$ can be expressed as:

$P_{M}=w_{M}^{3}$

The $P_{M}$ can also be expressed as $P_{M}=T_{M} w_{M}$.

From (3), the relation between $T_{M}$ and $w_{M}$ can be expressed as: $T_{M} \propto w_{M}{ }^{2}$.

The relation between speed, mechanical power and torque can be used to get optimal speed or torque to control the generator and achieve MPPT operation. Xu L cited the vector control technique which uses an asynchronous rotating reference frame theory, in which the $d$-axis is aligned with the stator flux space phasor. Using the MPPT algorithm, the reference value of torque is estimated which generates a reference value of quadrature axis current $i_{q \_ \text {ref }}$ and $i_{d_{-} \text {ref }}$ is taken as zero. These direct and quadrature axis reference rotor currents are compared with the actual value $i_{d}$ and $i_{q}$ to generate a rotor reference voltage $V_{d r}{ }^{*}$ and $V_{q r}{ }^{*}$. 
In the DFIG system configuration, the stator terminal is directly connected to the grid at a constant system voltage. Hence the stator flux is constant; as a result, the term $\frac{d\left|\varphi_{s}\right|}{d t}$ is zero. As the stator flux space phasor is aligned to d-axis, the torque expressions in the $\mathrm{d}$-q frame are as follows:

$$
\begin{aligned}
& T_{e m}=\frac{3}{2} P \frac{L_{m}}{L_{s}}\left(\varphi_{q s} i_{d r}-\varphi_{d s} i_{q r}\right) \\
& T_{e m}=-\frac{3}{2} P \frac{L_{m}}{L_{s}}\left|\overline{\varphi_{s}}\right| i_{q r} \\
& T_{e m}=K_{T} i_{q r}
\end{aligned}
$$

$$
\text { Where, } K_{T}=-\frac{3}{2} P \frac{L_{m}}{L_{S}}\left|\overline{\varphi_{s}}\right|
$$

According to (6), $i_{q r}$ is directly proportional to the torque. It is possible to control the torque by controlling the $i_{q r}$ component of the rotor current. Similarly, stator reactive power expressions in a $\mathrm{d}-\mathrm{q}$ frame are given as follows:

$Q_{s}=\frac{3}{2}\left(v_{q s} i_{d s}-v_{d s} i_{q s}\right)$

$Q_{s}=-\frac{3}{2} w_{s} \frac{L_{m}}{L_{s}}\left|\overline{\varphi_{s}}\right|\left(i_{d r}-\frac{\left|\overline{\varphi_{s}}\right|}{L_{m}}\right)$

$Q_{s}=K_{Q}\left(i_{d r}-\frac{\left|\overline{\varphi_{s}}\right|}{L_{m}}\right)$

Where, $K_{Q}=-\frac{3}{2} w_{s} \frac{L_{m}}{L_{S}}\left|\overline{\varphi_{s}}\right|$

The stator reactive power can be controlled independently by controlling the $i_{d r}$ component of the rotor current according to (9). Thus by selecting proper stator flux phasor orientation, torque and stator reactive power can be controlled by controlling the rotor direct and quadrature axis currents.

\subsection{Modified GSC control technique:}

The novelty of this paper is in the GSC control structure which can work as a shunt active filter to mitigate the grid current harmonics produced by the non-linear load, and simultaneously, can transfer the power from DFIG to a grid or vice versa for variable wind speed. Proposed modified SVPWM based GSC control technique to mitigate the grid current harmonics produced by the nonlinear load as shown in Fig. 2. The GSC supplies compensation current to make grid current sinusoidal.
The active power component of the dc-link current is generated by comparing the $\mathrm{V}_{\mathrm{dc}}$ reference with the $\mathrm{V}_{\mathrm{dc}}$ actual (DC link voltage) voltage using a PI regulator. A direct axis component of stator current $i_{d s}$ and load current $\mathrm{I}_{\mathrm{dl}}$ is obtained using a three-phase stator and load current converted into its equivalent two-phase $\mathrm{d}-\mathrm{q}$ components. The direct axis component of the grid current $I_{d g}$ is calculated using (10),

$I_{d g}=I_{d c}+I_{d s}-I_{d l}$

Where, $I_{d c}$ is the active power component of dc link current, $I_{d s}$ is the direct axis component of the stator current and $\mathrm{I}_{\mathrm{dl}}$ is the direct axis component of the load current. $\mathrm{I}_{\mathrm{qg}}$ is taken as zero as it does not draw reactive power from the grid. The $\mathrm{d}-\mathrm{q}$ component of the grid current $\mathrm{I}_{\mathrm{dg}}$ and $\mathrm{I}_{\mathrm{qg}}$ is converted to its equivalent threephase reference $\mathrm{I}_{\text {grid }}$ * current. To compensate the harmonics produced by the non-linear load, $\mathrm{I}_{\text {grid }}{ }^{*}$ is subtracted from the actual grid current $I_{\text {grid }}$ and the controlled value of $\mathrm{I}_{\mathrm{abc}}$ is generated. This $\mathrm{I}_{\mathrm{abc}}$ is used as a reference space phasor vector for the proposed SVPWM based modified GSC control technique.

1. Conventional Hysteresis Current Control technique (HCC): HCC technique works on feedback current control methods. Based on the hysteresis band limit, HCC generates PWM signals for converters. As shown in Fig. 3, the reference signal is generated using the control circuit is compared with the actual signal. When the actual current exceeds the upper limit of the hysteresis band, the upper switch is turned off and the lower switch is turned on. The current is forced to go in a downward direction. When the actual current crosses the lower limit of the hysteresis band, the lower switch is turned off and the upper switch is turned on. The current is forced to go in an upward direction [13].

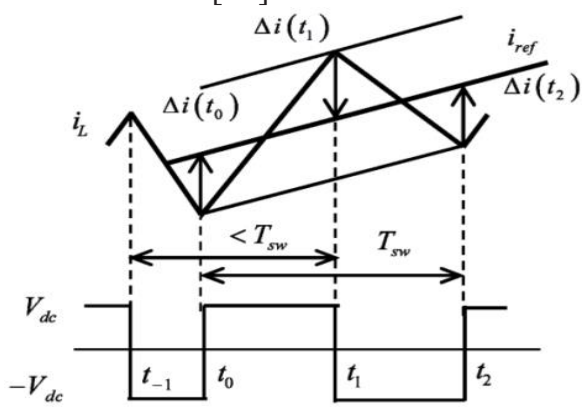

Fig. 3. Hysteresis current control PWM controller 


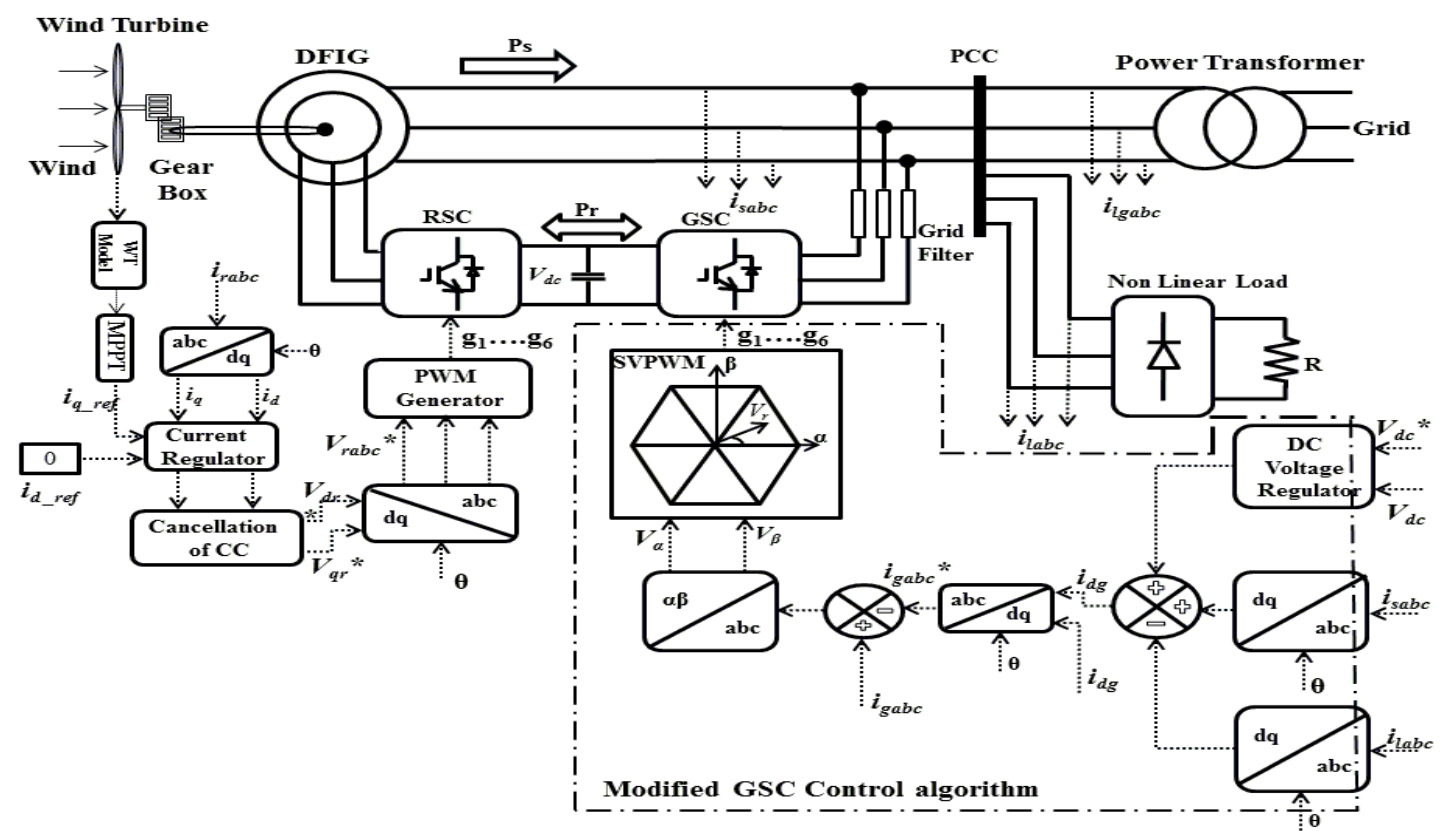

Fig. 2. Proposed SVPWM based Modified GSC control technique for DFIG based WECS.

2. Space Vector PWM Technique: The SVPWM technique is used to switch the semiconductor devices in the converter circuit. It offers low switching losses, more DC bus utilization and minimum \%THD in output quantity. The working principle of SVPWM is to generate reference voltage vector $\mathrm{V}_{\text {ref, }}$ which is the nearest value of the ideal voltage vector, by using eight separate voltage vectors as shown in Fig. 4. It shows six active vectors creating a hexagon with six sectors. $V_{\text {ref }}$ is generated based on the active switching vector.

$\overrightarrow{V_{\text {ref }}}=V_{\alpha}+V_{\beta}$

$V_{\text {ref }}=\sqrt{V_{\alpha}^{2}+V_{\beta}^{2}}$

$\theta=\tan ^{-1}\left(\frac{V_{\beta}}{V_{\alpha}}\right)$

Using Clark transformation $\overrightarrow{V_{\text {ref }}}$ in three-phase axis is: $\overrightarrow{V_{\text {ref }}}=\frac{2}{3}\left(V_{a} \cdot e^{j 0}+V_{b} \cdot e^{\frac{j 2 \pi}{3}}+V_{b} \cdot e^{\frac{j 4 \pi}{3}}\right)$

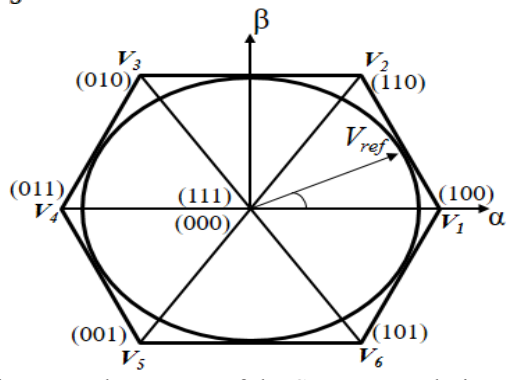

Fig. 4. The hexagonal structure of the SVPWM technique.

\section{Design Parameters}

\subsection{Design of the grid filter and the dc-link capacitor:}

The selection of the filter inductance $\mathrm{L}_{\mathrm{F}}$ must consider the ability to track the desired source current. The smaller the value of the filter, the higher is the ability to track the desired source current. However, a higher switching frequency is required to keep the ripple in the line current acceptably small. A practical choice of $\mathrm{L}_{\mathrm{F}}$ guarantees that the active filter can generate a current with a slope equal to the maximum slope of load current.

$$
L_{F} \leq \frac{V_{d c}-V_{n}}{\max \left|\frac{d i_{N L n}}{d t}\right|}
$$

Where $V_{n}$ is the line to neutral voltage and $i_{N L n}$ is the load current of phase $n$, respectively.

The capacitor size $C_{D C}$ can be estimated based on filter current $i_{F}$ and maximum accepted voltage ripple $\Delta V_{D C \max }$.

$$
V_{d c} \geq \frac{\max \left|\int_{0}^{t} i_{F}(t) d t\right|}{\Delta V_{d c \max }}
$$

\subsection{Selection of VSC rating:}

DFIG draws the lagging VAR to provide the excitation currents to the rotor winding. Total MVAR is demanded by DFIG is 0.8 MVAR (decided based on machine parameters). For unity power operation of stator voltage and current, the maximum reactive power demanded from the rotor side is $0.24 \operatorname{MVAR}\left(Q_{r \text { max }}=0.3 * 0.8\right.$ MVAR). The maximum rotor active power is calculated as follow:

$$
\mathrm{P}_{\mathrm{r} \max }=\mathrm{S}_{\max } * \mathrm{P}=0.3 * 2 \mathrm{MW}=0.6 \mathrm{MW}
$$

So the rating of VSC is given as:

$$
\mathrm{S}_{\text {rated }}=\sqrt{\mathrm{P}_{\mathrm{r} \text { max }}+\mathrm{Q}_{\mathrm{r} \max }}=0.646 \mathrm{MVA}
$$

So the MVA rating of VSC is $0.646 \mathrm{MVA}$.

\section{Performance Analysis Using Simulation Results}

\subsection{DFIG Operation with proposed modified GSC control technique:}

In the proposed technique, the DC link voltage regulation and mitigation of the grid current harmonics are achieved by the GSC control technique. Fig. 5 shows 
active power components of the dc-link current $I_{d c}$, the stator current Ids, the load current $\mathrm{I}_{\mathrm{dl}}$ and the grid current $\mathrm{I}_{\mathrm{dg}}$ for the wind speed $10.09 \mathrm{~m} / \mathrm{s}$. To verify the effectiveness of the proposed technique, the values of $\mathrm{I}_{\mathrm{dc}}$, $\mathrm{I}_{\mathrm{ds}}$, and $\mathrm{I}_{\mathrm{dl}}$ from Fig. 5 (a, b \& c) are placed in (10). The value of $I_{d g}$ obtained by (17) is exactly the same as the value obtained using the waveform shown in Fig. 5 (d).

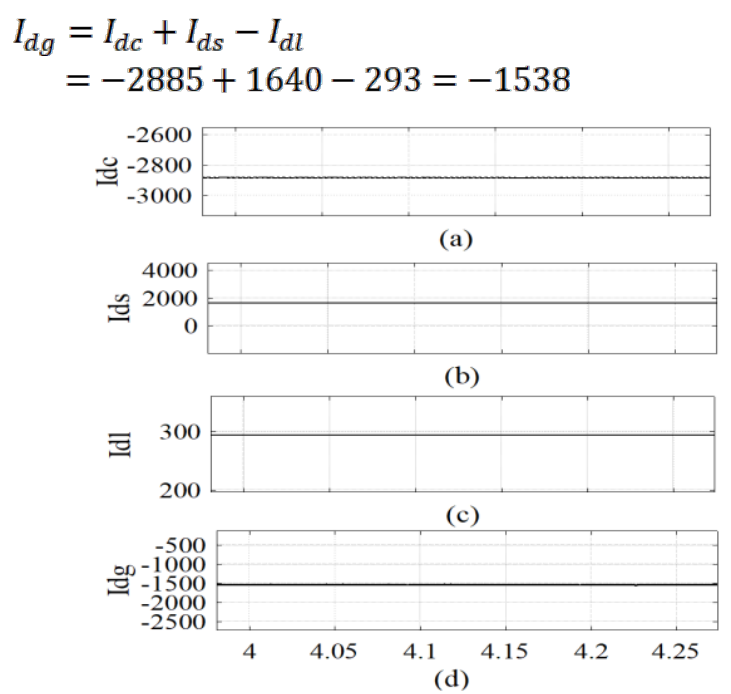

Fig. 5. Active component of (a) DC-link voltage, (b) stator current, (c) load current, (d) grid current.

The reference current $\mathrm{I}_{\text {grid }} *$ is obtained using $\mathrm{d}-\mathrm{q}$ transformation. The actual current $I_{\text {grid }}$ is compared with a reference current $\mathrm{I}_{\text {grid }} *$ to generate modulating signals for the PWM controller. The SVPWM controller is used to generate gate signals for GSC. The performance of various parameters of DFIG with the proposed technique at the wind speed of $10.09 \mathrm{~m} / \mathrm{s}$ is as shown in Fig. 6. DC link voltage $V_{d c}$ remains constant throughout the operating condition. There is no effect of the nonlinear load on the stator current $\mathrm{I}_{\text {sabc. }}$ It is observed from the waveforms that the proposed technique is able to mitigate the harmonics from grid current to make the grid current sinusoidal as well as transfer the power to the grid simultaneously. This direct axis component of the grid current $\mathrm{I}_{\mathrm{dg}}$ is able to control the DC link voltage as well as used to supply the compensation current to the grid.

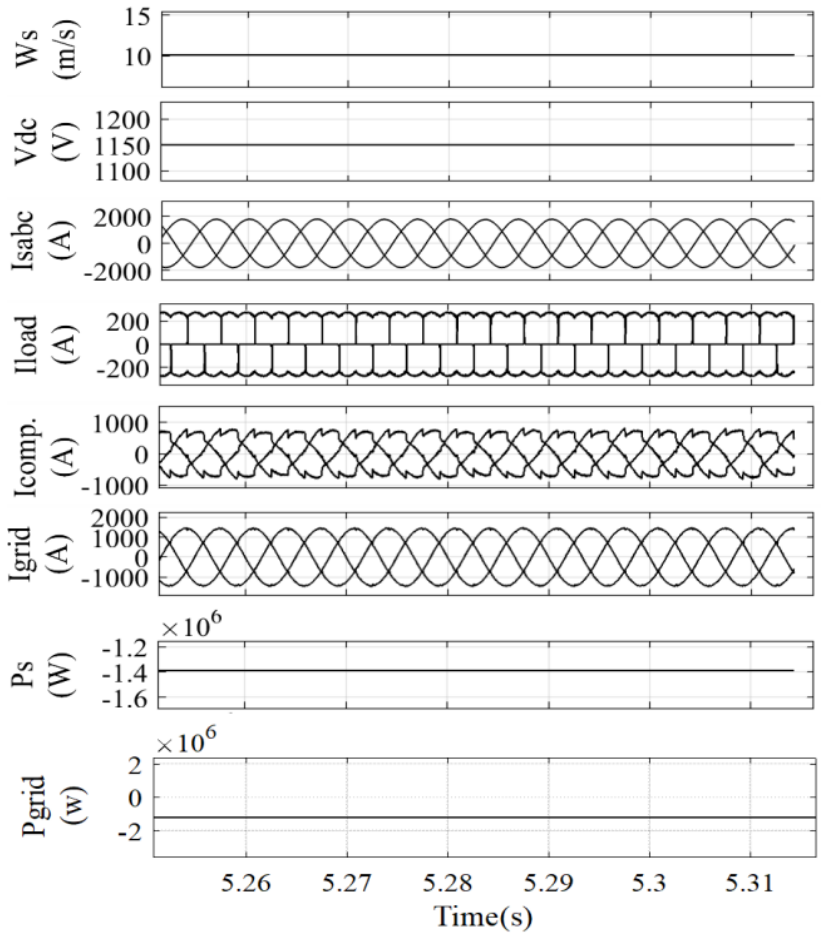

Fig. 6. DFIG performance with the proposed modified GSC control technique under $10.09 \mathrm{~m} / \mathrm{s}$ wind speed.

Fig. 7 depicts the grid current and the stator current with its \%THD when the system is connected with the nonlinear load. It is observed from the waveform that the effect of harmonics injected by the nonlinear load is completely mitigated using SVPWM based modified GSC control technique.

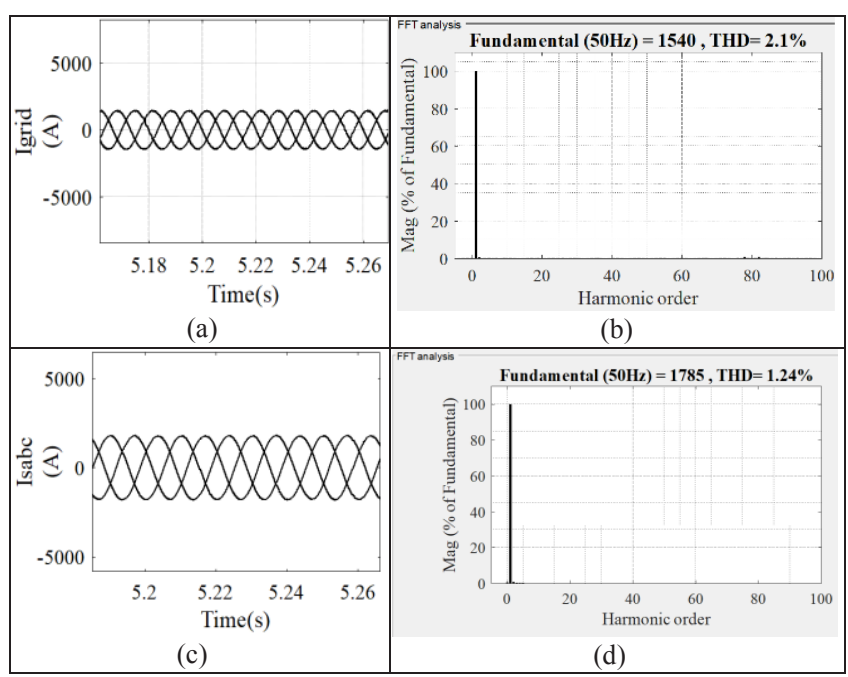

Fig. 7. DFIG performance under nonlinear load condition (a) $I_{\text {grid }}$ (grid current), (b) \% THD of $\mathrm{I}_{\text {grid }}$, (c) $\mathrm{I}_{\text {sabc }}$ (Stator current), (d) \%THD of $\mathrm{I}_{\text {sabc }}$.

\section{Performance Analysis Analytical Data \\ using}

Various values of $I_{d c}, I_{d s}, I_{d l}$ and $I_{d g}$ with different wind speeds are shown in Table 1 . The $\mathrm{I}_{\mathrm{dg}}$ value obtained using (17) is matched with the simulated value of $I_{d g}$. The comparison between $I_{\text {grid }} *$ and $I_{\text {grid }}$ carried out to generate the distortion component of the grid current $\Delta \mathrm{I}_{\text {grid. }}$. This $\Delta \mathrm{I}_{\text {grid }}$ was used to generate PWM signals using the SVPWM controller. Thus this proposed 
technique makes the grid current sinusoidal and balanced under the effect of nonlinear load.

Table 1. Proposed Modified GSC parameters under different wind speed

\begin{tabular}{|c|c|c|c|c|c|c|c|c|c|}
\hline $\begin{array}{l}\text { Sr. } \\
\text { No. }\end{array}$ & $\begin{array}{l}\text { DFIG } \\
\text { Mode }\end{array}$ & $\begin{array}{l}\text { Wind } \\
\text { Speed } \\
(\mathrm{m} / \mathrm{s})\end{array}$ & $\mathrm{I}_{\mathrm{dc}}$ & $\mathrm{I}_{\mathrm{ds}}$ & $\mathrm{I}_{\mathrm{dl}}$ & $\mathrm{I}_{\mathrm{dg}}$ & $\begin{array}{l}\text { Formula } \\
\mathrm{I}_{\mathrm{dg}}=\mathrm{I}_{\mathrm{dc}}+\mathrm{I}_{\mathrm{ds}} \\
-\mathrm{I}_{\mathrm{dl}}\end{array}$ & $\begin{array}{l}\mathrm{I}_{\text {grid }}{ }^{*} \\
\text { (A) }\end{array}$ & $\begin{array}{l}I_{\text {gid }} \\
\text { (A) }\end{array}$ \\
\hline 1 & \multirow{2}{*}{$\begin{array}{c}\text { Super } \\
\text { synchronous }\end{array}$} & 11.01 & -3650 & 1950 & 294 & -2000 & -1994 & 2030 & 2030 \\
\hline 2 & & 10.09 & -2885 & 1640 & 294 & -1538 & -1539 & 1550 & 1550 \\
\hline 4 & Synchronous & 9.175 & -2155 & 1358 & 294 & -1090 & -1091 & 1100 & 1100 \\
\hline 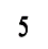 & \multirow{3}{*}{$\begin{array}{c}\text { Sub } \\
\text { Synchronous }\end{array}$} & 8.26 & -1535 & 1100 & 294 & -725 & -729 & 750 & 750 \\
\hline & & 7.34 & -1010 & 870 & 294 & -430 & -434 & 460 & 460 \\
\hline & & 6.74 & -580 & 670 & 294 & -200 & -204 & 230 & 230 \\
\hline
\end{tabular}

A comparison of $\mathrm{I}_{\text {grid }} \% \mathrm{THD}$ for HCC and SVPWM controller at different wind speed is shown in Table 2. Based on this comparison, the SVPWM controller is a better choice to mitigate the harmonics from grid current and improve the \%THD as compared to the HCC controller. So SVPWM based modified GSC control technique is a better solution for power quality improvement.

Table 2- Comparison of grid current \%THD

\begin{tabular}{|c|c|c|c|c|c|c|}
\hline $\begin{array}{c}\text { Sr. } \\
\text { No. }\end{array}$ & $\begin{array}{c}\text { Wind } \\
\text { Speed } \\
(\mathrm{m} / \mathrm{s})\end{array}$ & $\begin{array}{c}\text { \%THD } \\
\left(\mathrm{I}_{\text {grid }}\right)\end{array}$ & $\begin{array}{c}\text { \%THD } \\
\mathrm{I}_{\text {grid }} \\
\text { (nonlinear } \\
\text { load) }\end{array}$ & $\begin{array}{c}\text { \%THD } \\
\begin{array}{c}\mathrm{I}_{\text {grid }} \\
\text { (using } \\
\text { HCC) }\end{array}\end{array}$ & $\begin{array}{c}\text { \%THD } \\
\mathrm{I}_{\text {grid }} \text { (using } \\
\text { SVPWM) }\end{array}$ & $\begin{array}{c}\text { \% } \\
\text { Improvement } \\
\text { in THD }\end{array}$ \\
\hline 1 & 11.93 & 1.59 & 3.87 & 1.93 & 1.48 & $10 \%$ \\
\hline 2 & 11 & 2.08 & 5.02 & 2.48 & 2.06 & $8.37 \%$ \\
\hline 3 & 10.09 & 2.58 & 6.48 & 3.3 & 2.1 & $18.52 \%$ \\
\hline 4 & 9.175 & 3.25 & 8.81 & 4.66 & 2.78 & $21.34 \%$ \\
\hline 5 & 8.26 & 4.61 & 11.96 & 7.01 & 4.91 & $17.46 \%$ \\
\hline 6 & 7.34 & 6.8 & 15.63 & 12.95 & 9.3 & $26.35 \%$ \\
\hline 7 & 6.42 & 9.85 & 35.25 & 29.59 & 20.35 & $26.24 \%$ \\
\hline
\end{tabular}

A comparison of the grid current \%THD under normal conditions and nonlinear load conditions with two different PWM controllers, i.e. HCC and SVPWM, are shown in Fig. 8. From the comparison shown, it is clearly understood that by using SVPWM based modified GSC control technique, the grid current harmonics reduced significantly compared to the HCC based GSC control technique.

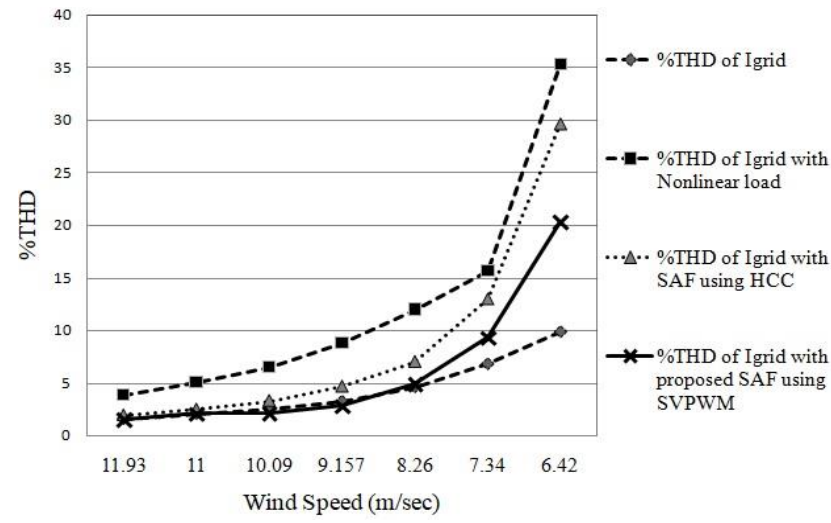

Fig. 8. Comparison of grid current \%THD

\section{Salient feature of the proposed technique}

1) The proposed SVPWM based modified GSC control technique helps to mitigate grid current harmonics and improved the \%THD profile as compare to HCC based GSC control technique.

2) The proposed SVPWM based modified GSC control technique reduces the device stress as there is no random switching.

3) The hardware and system configuration complexity is reduced by improving the control ability of GSC to carry out multiple functions in the same control algorithm.

4) Under the varying wind speed conditions, GSC was able to operate satisfactorily using the proposed modified GSC control technique.

\section{Conclusion}

The SVPWM based modified GSC control technique is proposed to mitigate the grid current harmonics produced by nonlinear load. From the waveform and analytical analysis presented in the paper, it is concluded that the proposed SVPWM based GSC control technique is much better than the HCC based GSC control technique to mitigate the grid current harmonics. The performance analysis of a DFIG under normal and varying wind speed conditions is carried out in detail. The MPPT phenomena are added in the RSC side control technique, to extract the maximum power from the wind. The proposed technique reduced device stresses as there is no random switching in SVPWM provided better voltage regulation, and easy to implement. The modification in the control strategy of the GSC to add the shunt active filter function is not create any effect on the power transfer capability of a DFIG. The proposed technique eliminates the requirements of extra power converter circuitry to mitigate the harmonics produced due to the nonlinear load.

\section{Appendix}

DFIG $=2.6 \mathrm{MW}, \mathrm{P}_{\text {rotor }}=0.6 \mathrm{MW}, \mathrm{P}_{\text {stator }}=2 \mathrm{MW}$, $\mathrm{V}_{\mathrm{s}}=690$ volt, Torque $=12732 \mathrm{~N}-\mathrm{m}$, Pole pair $=2, \mathrm{RPM}$ $=1500, \mathrm{I}_{\mathrm{s}}=1760 \mathrm{~A}, \mathrm{R}_{\mathrm{s}}=2.6 \times 10^{-3} \Omega, \mathrm{L}_{\mathrm{s} 1}=0.087 \times 10^{-3} \mathrm{H}$, $\mathrm{L}_{\mathrm{m}}=2.5 \times 10^{-3} \mathrm{H}, \quad \mathrm{R}_{\mathrm{r}}=2.9 \mathrm{e}-3 \Omega, \quad \mathrm{J}=127, \mathrm{D}=1 \times 10^{-3}$, $\mathrm{F}_{\mathrm{sw}}=4 \mathrm{kHz}$.

\section{References}

1. Siegfried Heier, "Grid Integration of Wind Energy Conversion Systems”,John Wiley \& Sons Ltd, 1998, ISBN 0-471-97143-X.

2. Renewable Energy Policy Network for the 21st Century (REN21), Renewable Global Status Report 2019-Infographics. 
3. The history and state of the art of variable-speed wind turbine technology. National Renewable Energy Laboratory, NREL/TP-500-28607, Golden.

4. F. Blaabjerg and Z. Chen, "Power Electronics for Modern Wind Turbines", Morgan \& Claypool publishers, 2014, pp: 11-20.

5. H.T.Jadhav, Ranjit Roy, "A comprehensive review on the grid integration of doubly fed induction generator", International Journal of Electrical Power \& Energy Systems, ISSN: 0142-0615, Vol: 49, Issue: 1, Page: 8-18, 2014.

6. F. Blaabjerg; Ke Ma, "Wind Energy Systems", 2017 IEEE Journals \& Magazines, 16 May 2017, pp: $2116-2131$.

7. H.-J. Wagner and J. Mathur, Introduction to Wind Energy Systems Basics, Technology and Operation. New York, NY, USA: Springer-Verlag, 2009

8. Mohd. Hasan Ali, "Wind Energy Systems: Solutions for Power Quality and Stabilization", CRC Press, 2012.

9. G M Joselin Herbert, S Iniyan and D Amutha, "A review of technical issues on the development of wind farms", Renew Sustain Energy Rev, pp.619641, 2014.

10. A. Gaillard, P. Poure and S. Saadate, "Active filtering capability of WECS with DFIG for grid power quality improvement", Proc. IEEE Int.Symp. Ind. Electron., Jun. 30, 2008, pp. 2365 -2370.

11. Mehdi T. Abolhassani, Prasad Enjeti, Hamid Toliyat, "Integrated Doubly Fed Electric Alternator/Active Filter (IDEA), a Viable Power Quality Solution, for Wind Energy Conversion Systems", IEEE Transactions on Energy Conversion, vol. 23, no. 2, June 2008.

12. A. Gaillard, P. Poure and S. Saadate, "Reactive power compensation and active filtering capability of WECS with DFIG without any overrating," Wind Energy, vol. 13, pp. 603-614, 2009.

13. N. K. Naidu, B. Singh, "Doubly fed induction generator for wind energy conversion systems with integrated active filter capabilities", IEEE Trans. Ind. Informat., vol. 11, no. 4, pp. 923-933, Aug. 2015.

14. Mona N. Eskander, Mahmoud A. Saleh and Mohsen M.T. El-Hagry, "Performance of Double Fed Induction Machine at Sub- and Super- Synchronous Speed in Wind Energy Conversion System", Journal of power electronics, Dec 02, 2014.

15. D. Somayajula and M. L. Crow, "An ultracapacitor Integrated Power Conditioner for Intermittency Smoothing and Improving Power Quality of Distribution Grid", IEEE Trans. Sustainable Energy, vol. 5, no. 4, pp.1145-1155, Oct. 2014.

16. M. Z. Sujod, I. Erlich, and S. Engel hardt, "Improving the reactive power capability of the DFIG-based wind turbine during operation around the synchronous speed", IEEE Trans. Energy Conv., vol. 28, no. 3, pp. 736-745, Sept. 2013. 